\title{
Six-minute walk test and incremental shuttle walk test in the evaluation of functional capacity in Chagas heart disease
}

\author{
Henrique Silveira Costa,*, Márcia Maria Oliveira Lima², Susan Martins Lage², Fábio Silva Martins da Costa', Pedro Henrique Scheidt \\ Figueiredo², Manoel Otávio da Costa Rocha' \\ 'Postgraduate Course of Infectious Diseases and Tropical Medicine, Department of Internal Medicine, Medical School and Hospital das Clínicas of the Universidade Federal \\ de Minas Gerais (UFMG), Belo Horizonte, Brazil \\ ${ }^{2}$ School of Biological and Health Sciences, School of Physiotherapy, Universidade Federal dos Vales do Jequitinhonha e Mucuri (UFVJM), Diamantina, Brazil \\ ${ }^{3}$ Rehabilitation Sciences Program, Department of Physiotherapy, Universidade Federal de Minas Gerais (UFMG), Belo Horizonte, Brazil
}

Chagas heart disease (CHD) leads to a progressive functional impairment. Field tests, as the 6-min walk test (6MWT) and the incremental shuttle walk test (ISWT), may be inexpensive approaches in the evaluation of functional capacity of these patients. The present study was addressed to compare the 6MWT and the ISWT measures, and to determine the accuracy of these tests in the identification of functional impairment in patients with CHD. Thirty-five patients with CHD $147.1 \pm 8.2$ years, NYHA I-III) were evaluated by echocardiography, cardiopulmonary exercise test (CPET), 6MWT, and ISWT. Correlations between the CPET (peak oxygen uptake [peak $\mathrm{VO}_{2}$ ] and the ratio between ventilation and the carbon dioxide production [VE/ $/ \mathrm{CO}_{2}$ slope]) and the field tests (walking distances) were also performed. The receiver operating characteristic (ROC) curve was selected to identify the best distances relat- ed to identify those patients with functional impairment. There was no difference between distances walked during the 6MWT and ISWT $(P=0.694)$. The Bland-Altman analysis showed good agreement between the field tests. Both 6MWT and ISWT correlated with peak $\mathrm{VO}_{2}$ ( $r=0.577, P<0.001$ and $r=0.587, P<0.001$, respectively) and ISWT correlated with $\mathrm{VE} / \mathrm{NCO}_{2}$ slope $(r=-0.339, P=0.003)$. The cutoff distances of $6 \mathrm{MWT}$ and ISWT to identify patients with peak $\mathrm{VO}_{2}$ less than $20 \mathrm{~mL} / \mathrm{kg} /$ min were $520 \mathrm{~m}$ and $400 \mathrm{~m}$, respectively, with no difference between the areas under ROC curves $(P=0.276)$. Both the 6MWT and the ISWT demonstrated accuracy in identify functional impairment in patients with $\mathrm{CHD}$, being useful tools for the risk stratification of these patients.

Keywords: Chagas disease, Exercise, Exercise test

\section{INTRODUCTION}

Chagas disease is a neglected tropical disease (World Health Organization, 2010) endemic in regions with scarce resources and with significant increase in prevalence in countries with large numbers of immigrants (Garcia et al., 2015). Chagas heart disease (CHD) is the clinical form with the worst prognosis (Dias et al., 2016; Rocha et al., 2007), defined by the presence of characteristic abnormalities of myocardial damage at electrocardiogram and/ or echocardiogram, with or without left ventricular dysfunction
(Andrade et al., 2011; Dias et al., 2016). The cardiac involvement leads to skeletal and cardiac muscles abnormalities (Montes de Oca et al., 2004), changes in lung function (Baião et al., 2013), inspiratory muscle weakness (Baião et al., 2013; Vieira et al., 2014), poor quality of life (Sousa et al., 2015), and reduced functional capacity (Baião et al., 2013; Mady et al., 2000), which should be regularly evaluated.

Patients with CHD may have functional impairment even in the presence of preserved left ventricular ejection fraction (LVEF) (Mady et al., 2000), and the cardiopulmonary exercise testing

${ }^{*}$ Corresponding author: Henrique Silveira Costa

(iD) https://orcid.org/0000-0002-1426-7246

Postgraduate Course of Infectious Diseases and Tropical Medicine, Department of Internal Medicine, Medical School and Hospital das Clínicas of the Universidade

Federal de Minas Gerais (UFMG), Rua Timbiras, 2505/903, Santo Agostinho,

30.140-063, Belo Horizonte, Minas Gerais, Brazil

Tel: +55-31-32754205, E-mail: henriquesilveira@yahoo.com.br

Received: July 15, 2018 / Accepted: August 21, 2018 
(CPET) is the gold standard in the assessment of physical function (Guazzi et al., 2008). The peak oxygen uptake (peak $\mathrm{VO}_{2}$ ) and the minute ventilation-carbon dioxide production slope $\left(\mathrm{VE} / \mathrm{VCO}_{2}\right.$ slope) can be directly measured by gas analysis and provide important clinical and prognostic information (Guazzi et al., 2008; Ritt et al., 2013). Nevertheless, the CPET is expensive and usually not available in endemic areas, limiting its applicability in clinical routine. Therefore, submaximal tests such as the 6-min walk test (6MWT) and the incremental shuttle walk test (ISWT) (Casillas et al., 2013) may be simple and inexpensive approaches to the functional assessment of patients with CHD.

The 6MWT is widely used in patients with CHD (Costa et al., 2014; Costa et al., 2017; Dourado et al., 2010). The test is easy to perform, inexpensive and well tolerated by patients (ATS Committee on Proficiency Standards for Clinical Pulmonary Function Laboratories, 2002). It has good reliability, moderate validity and ability to predict functional capacity in patients with heart failure (Casillas et al., 2013; Pollentier et al., 2010). However, the 6MWT is distance-limited, self-paced, and patients tend to select a comfortable speed (Morales et al., 1999), which could underestimate the functional evaluation.

Unlike the 6MWT, the ISWT is a symptom-limited test, with progressive increment of workload (Parreira et al., 2014; Singh et al., 1992). The regular increments make the test more similar to the CPET, and strong correlations are usually found between distance walked and $\mathrm{VO}_{2}$ peak in patients with different diseases, including heart failure (Morales et al., 1999; Parreira et al., 2014) and CHD (Alves et al., 2016).

Despite the common application of these tests in cardiac rehabilitation, no study was found that compared these measures in patients with CHD. Considering that Chagas cardiomiopathy is the most fibrosing and arrhythmogenic of known heart diseases and, consequently, with a worse prognosis (Botoni et al., 2013; Rocha et al., 2009), it is necessary to verify the performance of exercise testing in patients with Chagas cardiomyopathy. So, the present study aimed to compare the 6MWT and the ISWT measures in patients with CHD and to determine the accuracy of these field tests in the identification of functional impairment.

\section{MATERIALS AND METHODS}

This cross-sectional study was conducted at a referral center in the management of infectious and parasitic diseases. The research was carried out in accordance with the Declaration of Helsinki (World Medical Association, 2013) and was approved by the in- stitutional ethics committee (approval number: CAAE 03993912. 6.0000.5149). All the patients were informed about the objectives and agreed to voluntarily participate in the study.

\section{Study design}

The sample included CHD patients with different degrees of cardiac involvement. Eligibility criteria included the positive serology for Trypanosoma cruzi and the presence of arrhythmias and intraventricular and atrioventricular conduction disorders with or without left ventricular dysfunction (compatible with CHD) (Andrade et al., 2011). Patients with cardiopathy by any other causes, with comorbidities and unable to perform the exercise tests were excluded.

On the first day, the participants underwent clinical evaluation, echocardiography and CPET. The 6MWT and ISWT were performed on the following two days. A maximum interval of one week was allowed among the exercise tests. The investigators were blinded to the test results.

\section{Echocardiographic evaluation}

Echocardiography was performed according to recommendations of the American Society of Echocardiography (Lang et al., 2015) by one investigator who was blinded to the clinical evaluation of the patients. LVEF was obtained by modified Simpson rule. Early diastolic velocity (e') at the medial border of the mitral annulus was obtained and the ratio between peak mitral $\mathrm{E}$ and $\mathrm{e}^{\prime}$ (E/e') was calculated.

\section{Cardiopulmonary exercise testing}

The CPET was performed on a treadmill with the metabolic analysis system MetaLyzer 3B (Cortex Medical, Leipzig, Germany). The peak $\mathrm{VO}_{2}$ and minute ventilation-carbon dioxide production $\left(\mathrm{VE} / \mathrm{VCO}_{2}\right)$ slope were used as the primary endpoints in functional evaluation and obtained according to current guidelines (Guazzi et al., 2016).

\section{6-min walk test}

The 6MWT was guided by American Thoracic Society guidelines (ATS Committee on Proficiency Standards for Clinical Pulmonary Function Laboratories, 2002). During the 6MWT, the volunteers had to walk at the highest possible speed, without running, in a 30-m corridor. Words of encouragement were used every minute. Two tests were applied, with 15-min interval between them and the primary endpoint was the longest 6MWT distance, expressed in meters. 


\section{Incremental shuttle walk test}

The ISWT was performed using the protocol proposed by Singh et al. (1992). The test was applied in a 10-m course corridor marked out by two cones nine meters apart. The minimum speed achieved by patients on the test was controlled by signals from an audiotape previously recorded in regular intervals. The test was finished when the volunteer completed the 12 levels or could not achieve the distance target between cones within the intervals for two consecutive times. The primary endpoint was the longest ISWT distance, expressed in meters.

\section{Statistical analysis}

Statistical analyses were performed using SPSS ver. 17.0 (SPSS Inc., Chicago, IL, USA). Continuous data were expressed as mean and standard deviation and median and interquartile range, as appropriate. Categorical variables were shown as absolute number and percentage. Difference between distances walked during 6MWT and ISWT was verified by the Wilcoxon signed-rank

Table 1. Characteristics of the sample $(n=35)$

\begin{tabular}{lc}
\hline Variable & Value \\
\hline Characterization of the sample & \\
Age (yr) & $47.1 \pm 8.2$ \\
Male sex & $23(66)$ \\
Body mass index $\left(\mathrm{kg} / \mathrm{m}^{2}\right)$ & $26.5 \pm 4.6$ \\
NYHA functional class & \\
I & $20(57)$ \\
II & $09(26)$ \\
III & $06(17)$ \\
Echocardiographic variable & \\
LVEF (\%) & $59.0(41.0-64.0)$ \\
LVDD (mm) & $55.7 \pm 11.5$ \\
E/e' ratio & $12.2 \pm 4.2$ \\
Functional variable & \\
Peak VO $(\mathrm{mL} / \mathrm{kg} / \mathrm{min})$ & $26.3 \pm 8.1$ \\
VE $/ \mathrm{CCO}$ slope & $31.9 \pm 4.2$ \\
6MWT distance (m) & $571.0 \pm 81.7$ \\
ISWT distance (m) & $437.9(329.0-658.2)$ \\
ISWT level reached & \\
Level 5-8 & $23(66)$ \\
Level 9-11 & $5(14)$ \\
Level 12 & $7(20)$ \\
\hline
\end{tabular}

Values presented as mean \pm standard deviation, number $(\%)$, or median (interquartile range).

NYHA, New York Heart Association functional class; LVEF, left ventricular ejection fraction; LVDd, left ventricular end-diastolic diameter; E/e' ratio, ratio of the early diastolic transmitral flow velocity to early diastolic mitral annular velocity; peak $\mathrm{VO}_{2}$, peak oxygen uptake; $\mathrm{VE} / \mathrm{NCO}_{2}$, minute ventilation-carbon dioxide production; 6MWT, 6-min walk test; ISWT, incremental shuttle walk test. test. Correlations were evaluated by Pearson or Spearman correlation test. The significance level was set at $5 \%$. The agreement analysis between distances walked during submaximal field tests was verified by the Bland-Altman graph and the differences values were plotted against their mean. A ROC curve was constructed to verify the accuracy of $6 \mathrm{MWT}$ and ISWT in identifying those patients with peak $\mathrm{VO}_{2}$ below $20 \mathrm{~mL} / \mathrm{kg} / \mathrm{min}$ functional impairment, defined as values according to Webber classification (Weber et al., 1982). The statistical difference between the curves was determined by chi-square using the software MedCalc version 13.1.2.0 (MedCalc Software, Ostend, Belgium).

\section{RESULTS}

Patients with $\mathrm{CHD}(\mathrm{n}=35)$ were evaluated and the characteristics of the sample are shown in Table 1.

No significant difference was found between the distances traveled $(P=0.694)$. The agreement between the distances walked during field tests is demonstrated in the Bland-Altman diagram (Fig. 1). Only one pair (2.8\%) lies outside the limits of agreement. As shown in Fig. 2, significant correlation of peak $\mathrm{VO}_{2}$ was observed both with the 6MWT distance $(r=0.577, P<0.001)$ and with the ISWT distance $(r=0.587, P<0.001)$. The VE/VCO 2 slope correlated only with ISWT distance $(r=-0.339, P=0.003)$.

The area under the ROC curve showed that the distance walked during the 6MWT and the ISWT can identify patients with functional impairment (area under the curve [AUC], 0.77; 95\% confidence interval [CI], 0.61-0.93 and AUC, 0.87; 95\% CI, $0.75-0.99$, respectively). The optimal cut point value for $6 \mathrm{MWT}$

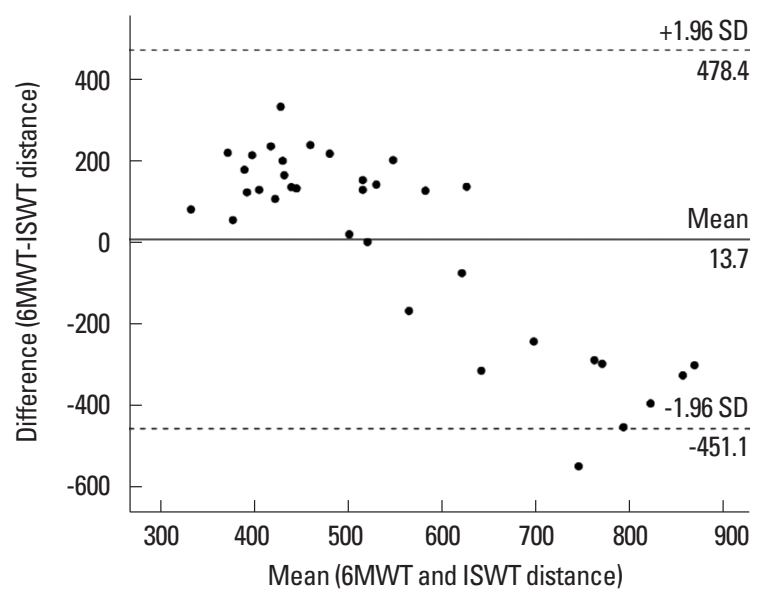

Fig. 1. Bland-Altman diagram showing the agreement between the distances walked by the 6MWT and ISWT. 6MWT, 6-min walk test; ISWT, incremental shuttle walk test; SD, standard devation. 

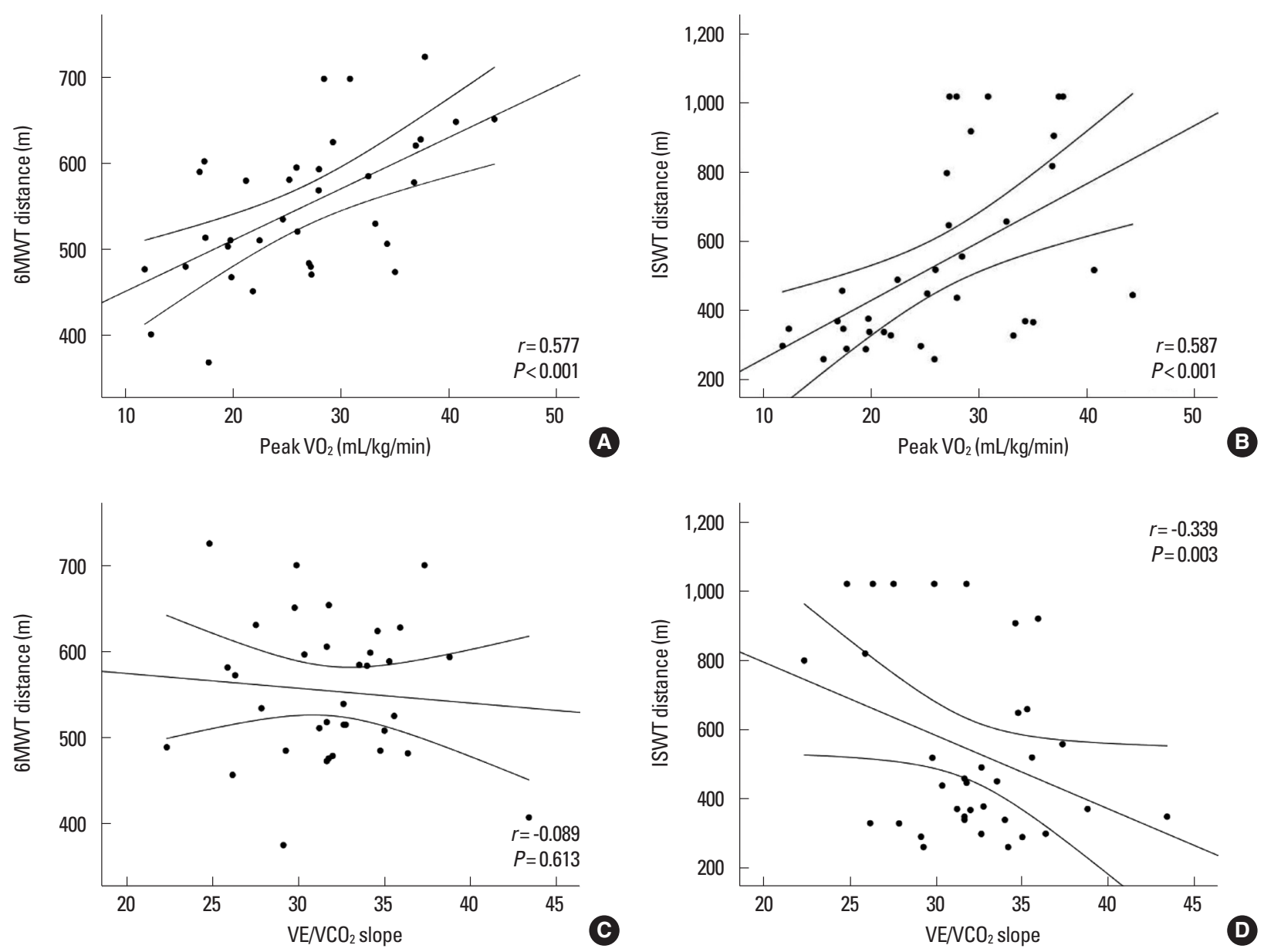

Fig. 2. Correlation of peak $\mathrm{VO}_{2}$ and $6 \mathrm{MWT}$ distance (A); peak $\mathrm{VO}_{2}$ and ISWT distance (B); VE/NCO 2 slope and 6MWT distance (C); VE/NCO 2 slope and ISWT distance (D). $\mathrm{VO}_{2}$, oxygen uptake; 6MWT, 6-min walk test; ISWT, incremental shuttle walk test; VENCO2, minute ventilation-carbon dioxide production.

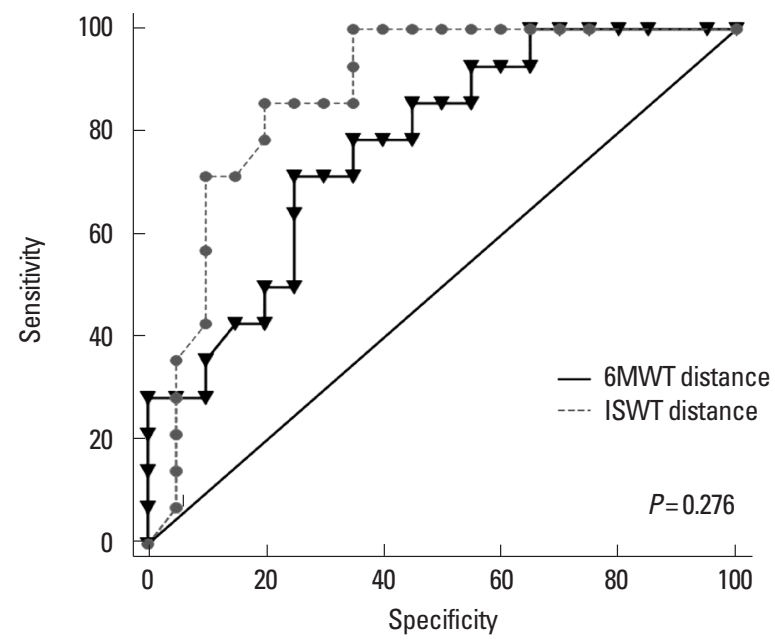

Fig. 3. Area under the receiver operating characteristic curve demonstrating the accuracy of the distances walked during the 6MWT and ISWT in identifying patients with functional impairment (peak $\mathrm{VO}_{2}<20 \mathrm{~mL} / \mathrm{kg} / \mathrm{min}$ ). $6 \mathrm{MWT}$, 6-min walk test; ISWT, incremental shuttle walk test; $\mathrm{VO}_{2}$, oxygen uptake. and ISWT to identify functional impairment was a distance less than $520 \mathrm{~m}$ and $400 \mathrm{~m}$, respectively. The sensibility and specificity for this cutoff value were, respectively, $75 \%$ and $71 \%$ for 6MWT distance and $80 \%$ and $86 \%$ for ISWT distance. As shown in Fig. 3, there was no significant difference between the areas under the curves $(P=0.276)$.

\section{DISCUSSION}

To the best of our knowledge, this is the first study that compared the 6MWT and ISWT distance and CPET variables in CHD patients with mild cardiac involvement. The main findings are (a) the good agreement between the 6MWT and ISWT distance, (b) the significant correlations between the 6MWT and ISWT distance and peak $\mathrm{VO}_{2}$ as well as between ISWT distance and $\mathrm{VE} / \mathrm{VCO}_{2}$, and (c) the good accuracy of both field tests in the identification of patients with functional impairment. 
Morales et al. (1999) analyzed the association between the 6MWT and the ISWT with peak $\mathrm{VO}_{2}$ (CPET) in 46 patients $(53 \pm$ 10 years, NYHA $2.8 \pm 0.7)$. They found that the correlation between the ISWT and peak $\mathrm{VO}_{2}$ was stronger $(r=0.83, P<0.001)$ than the 6MWT $(r=0.69, P<0.001)$. However, the present study found that the correlation between 6MWT and ISWT distance with peak $\mathrm{VO}_{2}$ were similar.

Another study (Pulz et al., 2008) verified the association between the 6MWT and ISWT distances and peak $\mathrm{VO}_{2}$ in heart failure patients ( $\mathrm{n}=63,51.3 \pm 10.2$ years, NYHA II-IV), with $25 \%$ of the sample being composed by patients with CHD. The authors verified both the 6MWT and ISWT had strong correlations with peak $\mathrm{VO}_{2}(r=0.76$ and $r=0.79$, respectively). They also found significant difference between the distances traveled during the submaximal field tests $(P<0.001)$, unlike the present study.

Most of patients in the present study were in NYHA functional class I and with preserved LVEF, which can partially explain the differences. We believe that field tests can underestimate the maximal functional capacity in patients with mild cardiac impairment. During the 6MWT, patients tend to select a comfortable speed, even if they can walk faster. In the ISWT, many of the patients with good functional capacity can reach the maximum level of the test (level 12), which occurred in the present study with $20 \%$ of the sample. However, patients rarely reached the maximum level of the CPET. Therefore, it appears that both field tests can be applied in the evaluation of functional capacity in CHD patients with good correlation with peak $\mathrm{VO}_{2}$, regardless of the degree of cardiac involvement. However, we recommend caution with this statement as a result of the small sample evaluated.

Our results also demonstrated that ISWT distance correlated weakly with $\mathrm{VE} / \mathrm{VCO}_{2}$ slope. This may have clinical relevance, since $\mathrm{VE} / \mathrm{VCO}_{2}$ slope is the only variable assessed by $\mathrm{CPET}$ considered an independent predictor of survival in CHD patients (Ritt et al., 2013). Indeed, survival data are not available in the present study, which is a limitation for the analysis of predictive validity, and the prognostic value of ISWT distance should be investigated in longitudinal studies.

Additionally, the present study verified that both field tests have good accuracy in the identification of CHD patients with functional impairment, without significant difference between the areas under the ROC curve. The cutoff points of distance walked with good sensitivity and specificity in identifying patients with functional impairment may be useful in the risk stratification of patients and in the adoption of preventive management based on physical exercise. Previous studies (Morales et al., 1999; Pulz et al., 2008) also reported the effectiveness of 6MWT and ISWT in identifying patients with heart failure and severely reduced peak $\mathrm{VO}_{2}$, showing cutoff values of 380 for ISWT and 490 for 6MWT (Pulz et al., 2008) or 450 for both (Morales et al., 1999).

These results have important clinical meaning in the setting of $\mathrm{CHD}$, since the endemic areas are generally poor, and the maximal exercise test may not be available. Furthermore, emerging studies have shown that exercise training can be beneficial to patients with Chagas disease (Fialho et al., 2012; Lima et al., 2010; Mediano et al., 2016) and field tests can also aid in risk stratification, which is very important for directing patients to cardiac rehabilitation (Bocchi et al., 2012). Therefore, both 6MWT and ISWT may be helpful in the functional evaluation and risk management of patients with CHD.

In conclusion, the 6MWT and the ISWT provide similar measures for assessment of the functional capacity in patients with mild CHD. Both field tests, inexpensive and easy-to-perform, can identify patients with functional impairment and have potential value for the assessment of patients with $\mathrm{CHD}$ in resource-limited areas.

\section{CONFLICT OF INTEREST}

No potential conflict of interest relevant to this article was reported.

\section{ACKNOWLEDGMENTS}

This study was funded by the FAPEMIG, Conselho Nacional de Desenvolvimento Científico e Tecnológico (CNPq), CAPES.

\section{REFERENCES}

Alves R, Lima MM, Fonseca C, Dos Reis R, Figueiredo PH, Costa H, Kreuser L, Nunes MC, Ribeiro AL. Peak oxygen uptake during the incremental shuttle walk test in a predominantly female population with Chagas heart disease. Eur J Phys Rehabil Med 2016;52:20-27.

Andrade JP, Marin Neto JA, Paola AA, Vilas-Boas F, Oliveira GM, Bacal F, Bocchi EA, Almeida DR, Fragata Filho AA, Moreira Mda C, Xavier SS, Oliveira Junior WA, Dias JC. I Latin American Guidelines for the diagnosis and treatment of Chagas' heart disease: executive summary. Arq Bras Cardiol 2011;96:434-442.

ATS Committee on Proficiency Standards for Clinical Pulmonary Function Laboratories. ATS statement: guidelines for the six-minute walk 
test. Am J Respir Crit Care Med 2002;166:111-117.

Baião EA, Costa Rocha MO, Lima MM, Beloti FR, Pereira DA, Parreira VF, Ribeiro AL, Britto RR. Respiratory function and functional capacity in Chagas cardiomyopathy. Int J Cardiol 2013;168:5059-5061.

Bocchi EA, Marcondes-Braga FG, Bacal F, Ferraz AS, Albuquerque D, Rodrigues Dde A, Mesquita ET, Vilas-Boas F, Cruz F, Ramires F, Villacorta H Jr, Souza Neto JD, Rossi Neto JM, Moura LZ, Beck-da-Silva L, Moreira LF, Rohde LE, Montera MW, Simões MV, Moreira Mda C, Clausell N, Bestetti R, Mourilhe-Rocha R, Mangini S, Rassi S, AyubFerreira SM, Martins SM, Bordignon S, Issa VS. Updating of the Brazilian guideline for chronic heart failure - 2012. Arq Bras Cardiol 2012; 98(1 Suppl 1):1-33.

Botoni FA, Ribeiro AL, Marinho CC, Lima MM, Nunes Mdo C, Rocha MO. Treatment of Chagas cardiomyopathy. Biomed Res Int 2013;2013: 849504.

Casillas JM, Hannequin A, Besson D, Benaïm S, Krawcow C, Laurent Y, Gremeaux V. Walking tests during the exercise training: specific use for the cardiac rehabilitation. Ann Phys Rehabil Med 2013;56:561-575.

Costa HS, Lima MM, Alencar MC, Sousa GR, Figueiredo PH, Nunes MC, Ribeiro AL, Rocha MO. Prediction of peak oxygen uptake in patients with Chagas heart disease: Value of the Six-minute Walk Test. Int J Cardiol 2017;228:385-387.

Costa HS, Lima MM, de Sousa GR, de Souza AC, Alencar MC, Nunes MC, Rocha MO. Functional capacity and risk stratification by the Six-minute Walk Test in Chagas heart disease: comparison with Cardiopulmonary Exercise Testing. Int J Cardiol 2014;177:661-663.

Dias JC, Ramos AN Jr, Gontijo ED, Luquetti A, Shikanai-Yasuda MA, Coura JR, Torres RM, Melo JR, Almeida EA, Oliveira W Jr, Silveira AC, Rezende JM, Pinto FS, Ferreira AW, Rassi A, Fragata AA Filho, Sousa AS, Correia D, Jansen AM, Andrade GM, Britto CF, Pinto AY, Rassi A Jr, Campos DE, Abad-Franch F, Santos SE, Chiari E, Hasslocher-Moreno AM, Moreira EF, Marques DS, Silva EL, Marin-Neto JA, Galvão LM, Xavier SS, Valente SA, Carvalho NB, Cardoso AV, Silva RA, Costa VM, Vivaldini SM, Oliveira SM, Valente VD, Lima MM, Alves RV. 2 nd Brazilian Consensus on Chagas Disease, 2015. Rev Soc Bras Med Trop 2016;49Suppl 1(Suppl 1):3-60.

Dourado KC, Bestetti RB, Cardinalli-Neto A, Cordeiro JA. Evaluation of the six-minute walk test in patients with chronic heart failure associated with Chagas' disease and systemic arterial hypertension. Rev Soc Bras Med Trop 2010;43:405-408.

Fialho PH, Tura BR, Sousa AS, Oliveira CR, Soares CC, Oliveira JR, Souza MV, Coelho MP, Souza FC, Cunha AB, Kopiler DA. Effects of an exercise program on the functional capacity of patients with chronic Chagas' heart disease, evaluated by cardiopulmonary testing. Rev Soc Bras Med Trop 2012;45:220-224.
Garcia MN, Murray KO, Hotez PJ, Rossmann SN, Gorchakov R, Ontiveros A, Woc-Colburn L, Bottazzi ME, Rhodes CE, Ballantyne CM, Aguilar D. Development of chagas cardiac manifestations among Texas blood donors. Am J Cardiol 2015;115:113-117.

Guazzi M, Arena R, Halle M, Piepoli MF, Myers J, Lavie CJ. 2016 Focused update: Clinical recommendations for cardiopulmonary exercise testing data assessment in specific patient populations. Circulation 2016;133:e694-711.

Guazzi M, Myers J, Abella J, Peberdy MA, Bensimhon D, Chase P, Arena $R$. The added prognostic value of ventilatory efficiency to the Weber classification system in patients with heart failure. Int J Cardiol 2008; 129:86-92.

Lang RM, Badano LP, Mor-Avi V, Afilalo J, Armstrong A, Ernande L, Flachskampf FA, Foster E, Goldstein SA, Kuznetsova T, Lancellotti P, Muraru D, Picard MH, Rietzschel ER, Rudski L, Spencer KT, Tsang W, Voigt JU. Recommendations for cardiac chamber quantification by echocardiography in adults: an update from the American Society of Echocardiography and the European Association of Cardiovascular Imaging. J Am Soc Echocardiogr 2015;28:1-39.e14.

Lima MM, Rocha MO, Nunes MC, Sousa L, Costa HS, Alencar MC, Britto RR, Ribeiro AL. A randomized trial of the effects of exercise training in Chagas cardiomyopathy. Eur J Heart Fail 2010;12:866-873.

Mady C, Ianni BM, Arteaga E, Salemi VM, de Carvalho Frimm C. Maximal functional capacity in patients with Chagas' cardiomyopathy without congestive heart failure. J Card Fail 2000;6:220-224.

Mediano MF, Mendes Fde S, Pinto VL, Silva GM, Silva PS, Carneiro FM, Sangenis LH, Saraiva RM, Xavier SS, Brasil PE, Hasslocher-Moreno AM, Sousa AS. Cardiac rehabilitation program in patients with Chagas heart failure: a single-arm pilot study. Rev Soc Bras Med Trop 2016;49:319-328

Montes de Oca M, Torres SH, Loyo JG, Vazquez F, Hernández N, Anchustegui B, Puigbó JJ. Exercise performance and skeletal muscles in patients with advanced Chagas disease. Chest 2004;125:1306-1314.

Morales FJ, Martínez A, Méndez M, Agarrado A, Ortega F, FernándezGuerra J, Montemayor T, Burgos J. A shuttle walk test for assessment of functional capacity in chronic heart failure. Am Heart J 1999;138(2 Pt 1):291-298.

Parreira VF, Janaudis-Ferreira T, Evans RA, Mathur S, Goldstein RS, Brooks D. Measurement properties of the incremental shuttle walk test. A systematic review. Chest 2014;145:1357-1369.

Pollentier B, Irons SL, Benedetto CM, Dibenedetto AM, Loton D, Seyler RD, Tych M, Newton RA. Examination of the six minute walk test to determine functional capacity in people with chronic heart failure: a systematic review. Cardiopulm Phys Ther J 2010;21:13-21.

Pulz C, Diniz RV, Alves AN, Tebexreni AS, Carvalho AC, de Paola AA, 
Almeida DR. Incremental shuttle and six-minute walking tests in the assessment of functional capacity in chronic heart failure. Can J Cardiol 2008;24:131-135.

Ritt LE, Carvalho AC, Feitosa GS, Pinho-Filho JA, Andrade MV, FeitosaFilho GS, Newby LK, Lopes RD. Cardiopulmonary exercise and 6-min walk tests as predictors of quality of life and long-term mortality among patients with heart failure due to Chagas disease. Int J Cardiol 2013; 168:4584-4585.

Rocha MO, Nunes MC, Ribeiro AL. Morbidity and prognostic factors in chronic chagasic cardiopathy. Mem Inst Oswaldo Cruz 2009;104 Suppl 1:159-166.

Rocha MO, Teixeira MM, Ribeiro AL. An update on the management of Chagas cardiomyopathy. Expert Rev Anti Infect Ther 2007;5:727-743.

Singh SJ, Morgan MD, Scott S, Walters D, Hardman AE. Development of a shuttle walking test of disability in patients with chronic airways obstruction. Thorax 1992;47:1019-1024.

Sousa GR, Costa HS, Souza AC, Nunes MC, Lima MM, Rocha MO. Health- related quality of life in patients with Chagas disease: a review of the evidence. Rev Soc Bras Med Trop 2015;48:121-128.

Vieira FC, de Melo Marinho PÉ, Brandão DC, Barbosae e Silva O. Respiratory muscle strength, the six-minute walk test and quality of life in Chagas cardiomyopathy. Physiother Res Int 2014;19:8-15.

Weber KT, Kinasewitz GT, Janicki JS, Fishman AP. Oxygen utilization and ventilation during exercise in patients with chronic cardiac failure. Circulation 1982;65:1213-1223.

World Health Organization. Working to overcome the global impact of neglected tropical diseases. First WHO report on neglected tropical diseases [Internet]. Geneva (Switzerland): World Health Organization; c2010 [cited 2018 Feb 3]. http://apps.who.int/iris/bitstream/10665/44440/ 1/97892415640902010.

World Medical Association. World Medical Association Declaration of Helsinki: ethical principles for medical research involving human subjects. JAMA 2013;310:2191-2194. 